\title{
Electrophysiologic Monitoring in the Intensive Care Unit
}

\author{
Rosamund A. Hill and Keith H. Chiappa
}

\begin{abstract}
Electroencephalography (EEG) and evoked potential studies are established monitoring tools in the neurological intensive care unit (ICU). These neurophysiologic techniques provide information on physiological state and response to therapy, and may aid diagnosis and prognosis. Serial studies or continuous monitoring may enable changes to be detected prior to irreversible deterioration in the patient's condition. Current computer technology allows simultaneous display and correlation of electrophysiologic parameters, cardiovascular state and intracranial pressure (ICP). Continuous EEG monitoring in the ICU has been shown to have a decisive or contributing impact on medical decision making in more than three-quarters of patients. In addition, continuous EEG monitoring has revealed previously unsuspected non-convulsive seizures in one-third of patients. SEPs and BAEPs can provide useful prognostic information in coma - however, these tests are etiologically nonspecific and must be carefully integrated into the clinical situation. Motor evoked potentials offer a potentially useful tool for evaluating motor system abnormalities in the ICU.
\end{abstract}

\begin{abstract}
Résumé: Surveillance électrophysiologique à l'unité de soins intensifs. L'électroencéphalographie et les études de potentiels évoqués sont des méthodes de surveillance reconnues à l'unité de soins intensifs neurologiques. Ces techniques neurophysiologiques fournissent de l'information sur l'état physiologique et sur la réponse thérapeutique et peuvent aider à établir le diagnostic et le pronostic. Des études en série ou une surveillance continue peuvent signaler des changements avant qu'une détérioration irréversible de la condition du patient ne survienne. La technologie informatique actuelle permet la visualisation et la corrélation simultanées des paramètres électrophysiologiques, de l'état cardiovasculaire et de la pression intracrânienne. Il a été démontré que le monitoring continu de l'EEG à l’unité de soins intensifs a un impact décisif ou tout au moins contribue au processus de décision médicale chez plus des trois-quarts des patients. De plus, le monitoring EEG continu a révélé des crises non convulsives qu'on n'avait pas soupçonnées antérieurement chez un tiers des patients. Les pontentiels évoqués sensitifs et auditifs peuvent fournir une information pronostique utile chez les patients comateux. Cependant, ces épreuves ne sont pas spécifiques quant à la cause et doivent être intégrées avec prudence à la clinique. Les potentiels évoqués moteurs sont un outil qui peut s'avérer utile dans l'évaluation des anomalies du système moteur à l'unité de soins intensifs.
\end{abstract}

Can. J. Neurol. Sci. 1994; 21: S12-S16

Neurophysiologic techniques (electroencephalogram and evoked potentials) can be used in the neurologic intensive care unit (neuro-ICU) for: 1) monitoring physiological state, 2) response to therapy, 3) supplementing or replacing the neurological examination in iatrogenic coma and/or paralysis, 4) prognosticating, and 5) defining the disease process. In addition, the computer technology that is being developed to manage the large volume of data generated by electrophysiologic monitoring may be useful for the analysis and display of other data collected in the neuro-ICU. For example, the same computer display may be used to show trends in the EEG, evoked potentials, intracranial pressure, blood pressure, heart rate, and others. Only these combined displays, which are currently available, allow effective study of the interaction between these variables.

Serial neurologic examination is not an adequate way to monitor central nervous system (CNS) levels of functioning in the neuro-ICU. Patients may be therapeutically paralyzed and serial neurologic examinations, even when performed conscien- tiously, are discontinuous, may miss important changes in the patients condition and vary according to the expertise of the examiner. A single or even repeated electrophysiologic study may suffer from the same problems - it is a discrete, brief sample of data that may not reflect the patient's overall condition. However, the electrophysiologic studies may yield brain wave patterns (e.g., suppression, burst-suppression, spindles, seizures, cycling) or evoked potentials which have possible therapeutic and prognostic significance.

Advances in technology have made possible the collection, storage and analysis of continuously collected EEG and repeated evoked potential studies. Such monitoring should enable the clinician to detect CNS injury at a time when meaningful intervention is still possible. For example, when temporal lobe herniation has

From the EEG/EP Laboratory, Massachusetts General Hospital, Boston.

Reprint requests to: Dr. K.H. Chiappa, EEG/EP Laboratory, Massachusetts General Hospital, Boston, Massachusetts, U.S.A. 02114 
reached the stage of third cranial nerve compression and pupillary dilation, a common signpost, some irreparable damage has probably already been done. In the case of arterial occlusion or vasospasm, clinical signs may be instantaneous or hours can intervene between the occlusion and clinical manifestations. In these cases, the EEG would change dramatically and could be used as a continuous monitor of cerebral function in the ICU. Studies of continuous EEG monitoring, transcranial doppler and cerebral blood flow are needed to evaluate this potential role of EEG monitoring.

\section{ELECTROENCEPHALOGRAPHY}

The most commonly used analysis technique for assessing EEG changes over time is the compressed spectral array (CSA) devised by Bickford. ${ }^{1}$ Many other computer analysis techniques have also been applied, including the calculation of peak and mean power, spectral edge frequencies, frequency bin activity totals, and frequency bin ratios. ${ }^{2-6}$

Changes in the EEG that may have pathological significance must be clearly differentiated from the normal cycling seen in the EEG. Fluctuations in EEG and other physiologic parameters may reflect the sleep/wake cycle, stages of normal sleep, or cycling in pathologic states. EEG variation has been seen in comatose patients for approximately 25 years. ${ }^{7-11}$ Prognosis has been reported to be better when the EEG pattern is variable; Bricolo and co-workers ${ }^{12,13}$ and Bergamasco et al.$^{8,9}$ found that a monophasic or unvaried EEG pattern carried a significantly worse prognosis than an alternating or cycling pattern. In some cases, typical EEG sleep patterns were seen. Alexandre et al. ${ }^{14}$ found a very good correlation between the presence of REM sleep and outcome. If sleep patterns were not present, a cycling or bi-phasic record still predicts a better outcome. In one study, an unfavorable outcome was noted in $95 \%$ of patients whose CSAs were slow and monotonous. ${ }^{15}$

Several investigators have begun to routinely use continuous neurophysiologic monitoring for patient management. The impact of this monitoring on clinical decision making has been investigated by Jordan. ${ }^{16}$ The EEGs were continuously monitored in 73 patients. The impact was considered "decisive" when at least one major clinical decision, such as initiating or changing antiepileptic therapy or transporting the patient out of the NICU, was made solely on the basis of the EEG findings. The impact was considered "contributory" when at least one major decision was based on the EEG plus clinical examination. The EEG was found to have a decisive or contributing impact on medical decision making in $82 \%$ of patients. A follow-up study ${ }^{17}$ of $100 \mathrm{ICU}$ patients monitored with EEG revealed 29 with nonconvulsive seizures (NCS), $65 \%$ of whom had nonconvulsive status epilepticus (NCSE). Twenty-one percent of the NCS patients were initially (without EEG) misdiagnosed with nonepileptic conditions. Sixty-eight percent of NCS patients compared to $27 \%$ of non-NCS patients died or required custodial care. Seizure activity, even without motor manifestations, results in detrimental effects including increased intracranial pressure, increased cerebral blood flow and oxygen use. ${ }^{18}$ Young et al. ${ }^{19}$ studied 350 comatose ICU patients with EEG and found 41 with epileptiform activity, one-third of whom had clinical seizures. Twenty-one had anoxic-ischemic encephalopathy and all 19 of these who had generalized epileptiform activity died. Further studies are needed to determine the impact of early recognition and treatment of unsuspected seizure activity on outcome.
Whereas the automatic, computerized detection of focal cerebral dysfunction secondary to ischemia or mass lesions can be accomplished using a variety of extracted features, seizure detection is best accomplished using pattern recognition. Seizure detection software has been routinely applied in epilepsy monitoring units ${ }^{20}$ and these algorithms can be effectively applied to the ICU so that the tools are at hand to implement effective monitoring protocols for these patients. The role of EEG monitoring in patients in the neuro intensive care unit has been described by several authors including Suzuki et al., ${ }^{4,21-24}$

\section{Evoked Potentials}

Evoked potentials have begun to be utilized for following the level of functioning of the CNS in comatose patients. Clinical utility of brainstem auditory (BAEP) and short-latency somatosensory (SEP) evoked responses stems from the close relationship between the EP waveforms and specific anatomic structures. This specificity allows localization of conduction defects to within a centimetre or so (BAEPs) or a few centimetres (SEPs). In addition, these EPs are essentially unaffected by general anesthesia, and even high-dose barbiturate therapy (sufficient to render the EEG "flat") for raised ICP does not significantly alter the EP components. These factors of anatomic specificity and physiologic and metabolic immutability are the basis of the clinical utility of EPs. They thus provide a reliable look at "physiologic anatomy". However, abnormalities demonstrated by these tests are etiologically non-specific and must be carefully integrated into the clinical situation by a physician familiar with the clinical use of the tests.

The SEP shows special promise in the ICU field because components generated supratentorially in the thalamus and primary sensory cortex can be identified and followed over time. Shifts in intracranial structures leading to herniation syndromes can be expected to be reflected in abnormalities in this test, whereas BAEPs are generated entirely at or below the lower midbrain and would be less likely to be affected.

\section{Brainstem Auditory Evoked Potentials}

Use of BAEPs to assess brainstem integrity in comatose patients is, to some extent, limited by the anatomic specificity of the test. BAEPs can be normal in patients completely paralyzed from brainstem infarction. Thus, there can be major brainstem lesions without involvement of the auditory tracts and therefore normal BAEPs are not indicative of functional integrity of the entire brainstem. Since BAEPs are generated by structures mostly below midbrain levels, progressive space-taking lesions in the cerebral hemispheres will not produce BAEP changes until structures in the low midbrain or below are involved. Impressions of clinical utility of BAEPs in comatose patients have varied according to whether or not these factors were taken into account, the statistical limits of normality used in interpretation and the time of BAEP testing in relation to the cerebral insult. ${ }^{25-46}$

The limited statistical relationship between BAEP results and clinical outcome is not particularly useful in the clinical situation where one is faced with an individual patient; there is no way of knowing into which outcome group the individual patient will fall, except in those who are the worst clinically. In these patients the clinicians do not need prognostic help. However, if damage to the peripheral hearing apparatus can be ruled out, 
the absence of BAEPs is strongly correlated with a poor outcome. The addition of this data to other prognostic indicators, none of which by themselves are conclusive, may be helpful in assigning a patient to a poor prognosis category with a high degree of certainty. Nagao et al. ${ }^{47}$ have'suggested that immediate medical or surgical decompression of ICP should be performed when ICP approaches $30 \mathrm{~mm} \mathrm{Hg}$ with significant prolongation of wave V latency.

The functional integrity of the brainstem has been studied using BAEPs in brain-dead patients. ${ }^{25,36,48-51}$ However, a majority of these patients lack the eighth nerve activation potential (wave I). Without wave I present, no inferences can be made as to the localization of the interruption of the auditory signal since the integrity of the peripheral apparatus in any individual patient is often not known. For example, a traumatic transverse fracture of the temporal bone might have damaged the cochlea, or, in a case where the clinical history is poor, the patient might have had a pre-existing deafness in the only ear available for BAEP testing. Wave I absence in these patients is thought to be secondary to interference with the VIIIth nerve and cochlear blood supply which is derived primarily from intracranial circulation via the anterior inferior cerebellar and internal auditory arteries. However, if wave I is present initially, serial testing may allow deterioration in the BAEPs to be followed and clinically correlated.

Patients in an ICU are vulnerable to damage to the peripheral hearing apparatus via antibiotics, infections, etc. Since conventional behavioural hearing test may be difficult to perform reliably in infants and children, the use of BAEPs in this patient population has been the subject of much attention. Hecox and Galambos, ${ }^{52}$ Sohmer and Feinmesser, ${ }^{53}$ Mokotoff et al., ${ }^{54}$ Smith and Simmons ${ }^{55}$ and Starr et al. ${ }^{56}$ studied normal and hearingimpaired infants and children, comparing BAEP results with those obtained from conventional audiometric testing; good correlations were found. The importance and utility of testing hearing function in at-risk patients has been shown in several studies.

\section{Somatosensory Evoked Potentials}

Electrical stimulation of large nerves (e.g., median, ulnar) in the upper limbs elicits a set of waveforms that are generated in the brachial plexus, upper cervical cord, dorsal column nuclei, thalamic nuclei (presumably mostly VPL) and primary sensory cortex. These waveforms, similar to BAEP waves, are extremely resistant to being altered by non-pathologic factors. For example, SEPs can be recorded unchanged from patients whose EEG has been rendered "flat" during high dose barbiturate therapy for increased ICP, and other studies also show no significant effects on SEPs relative to clinical interpretation..$^{41.57 .58}$

Goldie et al. ${ }^{25}$ studied median SEPs in 36 patients who were in coma (clinically poorly responsive but with some preservation of brainstem function) from various etiologies. All had identifiable Erb's Point and P/N13 waves. Twelve patients (33\%) had no identifiable N19-P23 waves bilaterally; 6 of them died and 6 remained in a vegetative state. This finding remains one of the best prognostic rules in these patients, i.e., if a comatose patient is missing N19-P22 bilaterally, then that patient's outcome will be a persistent vegetative state at best. Subsequent studies in adults ${ }^{40,59}$ and children ${ }^{42,45,60,61}$ have revealed no exceptions to this rule. A review of 14 international studies (summarized in Table 9-1 in Chiappa and Hoch $^{62}$ ) encompassing 629 comatose patients revealed that 258 had bilaterally absent N19/P22 and
$83 \%$ of these died, $11 \%$ were left in a persistent vegetative state and $6 \%$ were left disabled ( 3 described as "dependent" and 10 "severe" without further descriptions) - only 2 were reported to have had a good recovery ( 1 without further clinical details and 1 a child who had suffered a lightening strike). This bilateral absence of N19-P22 needs to be clearly distinguished from unilateral absence since these patients may have a good outcome (although the absent EP waveforms indicates that the functional recovery of the involved limbs will be poor).

Preservation of the P/N13 wave in $69 \%$ of brain-dead patients indicates that the stimulus-generated signal has reached the spinal cord. Failure of further rostral conduction, indicated by lack of subsequent waves, is then an indicator of brainstem dysfunction. This situation contrasts with the BAEP where $77 \%$ of brain-dead patients did not have a wave (wave I) that proved the input signal had activated the VIIIth nerve.

The variable preservation of $\mathrm{P} / \mathrm{N} 13$ in brain-dead patients is probably the result of an interaction between cessation of intracranial circulation (due to increased intracranial pressure following cerebral necrosis) and the pattern of blood supply to the lower medulla. The site of P/N13 generation, in the region of the cervico-medullary junction, is at an interface between intracranial and extracranial blood supply. Since the dorsal column nuclei are the most likely candidates for the P/N13 generator, this suggests that these nuclei were functionally preserved in $69 \%$ of brain-dead patients. In a multicenter study, $57 \%$ of 127 brain-dead patients had neuropathologically intact cervicomedullary junctions, ${ }^{63}$ although the state of the dorsal column nuclei themselves was not systematically defined. Preservation of the lower medulla and P/N13 might also parallel preservation of some cerebral respiratory function in patients who meet all other criteria of brain death.

Eldridge et al ${ }^{64}$ evaluated the use of cortical SEPs to monitor cerebral perfusion pressure in patients with raised intracranial pressure. They found the SEP was not abolished until the cerebral perfusion pressure was as low as $25 \mathrm{~mm} \mathrm{Hg}$, which is far below the generally accepted level of $40-60 \mathrm{~mm} \mathrm{Hg}$. This suggests that the SEP is resistant to levels of ischemia that could compromise cerebral cortex outside the somatosensory pathways. ${ }^{65}$ SEP testing is therefore not routinely used to monitor focal cerebral ischemia. Systematic studies of SEPs in herniation syndromes have not been reported.

\section{Motor Evoked Potentials}

The motor cortex in awake humans may be stimulated electrically from electrodes on the scalp or magnetically and the resultant muscle twitch recorded peripherally gives a measure of function in the motor system tracts. Studies of MEPs in stroke have provided very reliable prognostic information. ${ }^{66.67}$ Absence or low amplitude of MEPs was always associated with a very poor outcome, and this was occasionally seen even when the SEPs were normal. Stroke patients followed over time showed that improvement in MEP amplitude paralleled clinical improvement. ${ }^{67}$ Motor evoked potentials have also been investigated in comatose patients in the ICU with inconsistent results regarding their prognostic significance, ${ }^{68-71}$ although further studies are required.

\section{ACKNowledGeMENT}

Portions of text taken with permission from Chiappa and Hoch. ${ }^{62}$ 


\section{REFERENCES}

1. Bickford RG. Newer methods of recording and analyzing EEG. In: Current Practice of Clinical Electroencephalography. New York: Raven Press, 1979.

2. Chiappa KH, Ropper AH. Long-term electrophysiologic monitoring of patients in the neurology intensive care unit. Seminars in Neurology 1984; 4(4): 469-479.

3. Bricolo A, Faccioli F, Grosslercher JC, et al. Electrophysiological monitoring in the intensive care unit. Electroenceph Clin Neurophysiol 1987; 39 (Suppl): 255-263.

4. Suzuki A, Mori N, Hadeishi H, Yoshioka K, Yasui N. Computerized monitoring system in neurosurgical intensive care. J Neurosci Meth 1988; 26: 133-139.

5. Garcia-Larrea L, Bertrand O, Artru F, Pernier J, Mauguiere F. Brain-stem monitoring. II preterminal BAEP changes observed until brain death in deeply comatose patients. Electroenceph Clin Neurophysiol 1987; 68: 446-457.

6. Hilz MJ, Litscher G, Weis M, et al. Continuous multivariable monitoring in neurological intensive care patients - preliminary reports on four cases. Intensive Care Medicine 1991; 17(2): 8793.

7. Passouant P, Cadilhac J, Delange M, Baldy-Moulinier M, Kassabgui ME. Differential electrical stages and cyclic organization of post-traumatic comas; polygraphic recording of long duration. Electroencephalog Clin Neurophysiol 1965; 18: 720.

8. Bergamasco B, Bergamini L, Doriguzzi T. Clinical value of the sleep electroencephalographic patterns in post-traumatic coma. Acta Neurol Scandinav 1968; 44: 495-511.

9. Bergamasco B, Bergamini L, Dorriguzzi T, et al. EEG sleep patterns as a prognostic criterion in post-traumatic coma. Electroencephalogr Clin Neurophysiol 1968; 24: 374-377.

10. Bricolo A, Gentilomo A, Rosadini G, Rossi GF. Long-lasting posttraumatic unconsciousness. Acta Neurol Scandinav 1968; 44: $512-532$.

11. Hughes JR, Cayaffa J, Leestma J, Mizuma Y. Alerting "waking" and "sleeping" EEG patterns in a deeply comatose patient. Clin Electroencephalogr 1972; 3: 86-93.

12. Bricolo A, Turella G, Ore GD, Terzian H. A proposal for the EEG evaluation of acute traumatic coma in neurosurgical practice. Electroencephalogr Clin Neurophysiol 1973; 34: 789.

13. Bricolo A. Electroencephalography in Neurotraumatology. Clin Electroenceph 1976; 7: 184-197.

14. Alexandre A, Rubini L, Nertempi P, Farinello C. Sleep alterations during post-traumatic coma as a possible predicator of cognitive defects. Acta Neurochirurgica 1979; 28 (Suppl): 188-192.

15. Bricolo A, Turrazzi S, Faccioli F, et al. Clinical application of compressed spectral array in long-term EEG monitoring of comatose patients. Electroenceph Clin Neurophysiol 1978; 45: 211-225.

16. Jordan KG. Continuous EEG and evoked potential monitoring in the neuroscience intensive care unit. J Clin Neurophysiol 1993; 10(4): 445-475.

17. Jordan KG. Nonconvulsive seizures and nonconvulsive status epilepticus detected by continuous EEG monitoring in the neuroICU. Neurology 1992; 42 (Suppl 3): 194.

18. Nevander G, Ingvar M, Auer R, Siesjo BK. Status epilepticus in well-oxygenated rats causes neuronal necrosis. Ann Neurol 1985; 18: 281-290.

19. Young GB, McLachlan R, Demelo J, Kreeft J. The importance of epileptiform EEG activity in the comatose patient in the general ICU. Neurology 1993; 43 (Suppl 2): A229.

20. Gotman J. Automatic seizure detection: improvements and evaluation. Electroencephalogr Clin Neurophysiol 1990; 76(4): $317-$ 324.

21. Suzuki A, Yoshioka K, Yasui N. Clinical application of EEG topography in cerebral ischemia: detection of functional reversibility and hemodynamics. Brain Topography 1990; 3(1): 167-174.

22. Jordan KG. Correlative Xenon-enhanced CT cerebral blood flow (XeCTCBF) and EEG to functionally stratify acute cerebral infarction. Neurology 1991; 41 (Suppl 1): 336.
23. Rivierez M, Landau-Ferey J, Grob R, Grosskopf D, Philippon J. Value of electroencephalogram in prediction and diagnosis of vasospasm after intracranial aneurysm rupture. Acta Neurochirurgica 1991; 110(1-2): 17-23.

24. Labar DR, Fisch BJ, Pedley TA, Fink ME, Solomon RA. Quantitative EEG monitoring for patients with subarachnoid hemorrhage. Electroencephalogr Clin Neurophysiol 1991; 78(5): 325-332.

25. Goldie WD, Chiappa KH, Young RR, Brooks EB. Brainstem auditory and short-latency somatosensory evoked responses in brain death. Neurology 1981; 31: 248-256.

26. Hall JW, Huang-fu M, Gennarelli TA. Auditory function in acute severe head injury. Laryngoscope 1982; 92: 883-890.

27. Rappaport M, Hall K, Hopkins HK, Belleza T. Evoked potentials and head injury. 1. Rating of evoked poetential abnormality. Clin Electroenceph 1981; 12: 154-166.

28. Rappaport M, et al. Evoked potentials and head injury. 2. Clinical Applications. Clin Electroencephalogr 1981; 12: 167-176.

29. Tsubokawa T, Nishimoto H, Yamamoto T, et al, Assessment of brainstem damage by the auditory brainstem responses in acute severe head injury. J Neurol Neurosurg Psychiatry 1980; 43: 1005-1011.

30. Greenberg RP, Becker P, Miller JD, Mayer DJ. Evaluation of brain function in severe human head trauma with multimodality evoked potentials. Part 1. Evoked brain injury potentials, methods, and analysis. Part 2. Localization of brain dysfunction and correlation with post-traumatic neurological conditions. J Neurosurg 1977; 47: 150-177.

31. Uziel A, Benzech J. Auditory brainstem responses in comatose patients: relationship with brain-stem reflexes and levels of coma. Electroencephalogr Clin Neurophysiol 1978; 45: 515-524.

32. Seales DM, Rossiter VS, Weinstein ME. Brainstem auditory evoked responses in patients comatose as a result of blunt head trauma. J Trauma 1979; 19: 347-353.

33. Sanders RA, Smriga DJ, McCullough DW, Duncan PG. Auditory brainstem responses in patients with global cerebral insults. J Neurosurg 1981; 55: 227-236.

34. Karnaze DS, Marshall LF, Bickford RG. EEG monitoring of clinical coma: spectral array. Neurology 1982; 32: 289-292.

35. Stern BJ, Krumholz A, Weiss H, Goldstein P, Harris KC. Evaluation of brainstem stroke using brain stem auditory responses. Stroke 1982; 13: 705-711.

36. Klug N. Brainstem auditory evoked potentials in syndromes of decerebration, the bulbar syndrome and in central death. J Neurol 1982; 227: 219-228.

37. Goitein KJ, Amit Y, Fainmesser P, Sohmer H. Diagnostic and prognostic value of auditory nerve brainstem evoked responses in comatose children. Critical Care Medicine 1983; 2: 91-94.

38. Narayan RK, Greenberg RP, Miller JD, et al. Improved confidence of outcome prediction in severe head injury. A comparative analysis of the clinical examination, multimodality evoked potentials, CT scanning, and intracranial pressure. J Neurosurg 1981; 54: 751-762.

39. Hall JW, Huang-fu M, Gennarelli TA, et al. AEPs, impedance measures, and diagnostic speech audiometry in severe head injury. Otolarng - Head and Neck Surg 1983; 91: 50-60.

40. Anderson DC, Bundlie S, Rockswold GL. Multimodality EPs in closed head trauma. Arch Neurol 1984; 41: 369-374.

41. Newlon PG, Greenberg RP, Enas GG, Becker DP. Effects of therapeutic pentobarbital coma on multimodality EPs recorded from severely head-injured patients. Neurosurg 1983; 12: 613-619.

42. Lutschg J, Pfenninger J, Ludin HP, Vassella F. BAEPs and early SEPs in neurointensively treated comatose children. Am J Dis Child 1983; 137: 421-426.

43. Taylor MJ, Houston BD, Lowry NJ. Recovery of BAEPs after a severe hypoxic ischemic insult. N Eng J Med 1983; 309: 11691170.

44. Rosenberg C, Wogensen K, Starr A. Auditory brain-stem and middleand long-latency EPs in coma. Arch Neurol 1984; 41: 835-838. 
45. Frank LM, Furgiuele TL, Etheridge JE Jr. Prediction of chronic vegetative state in children using evoked potentials. Neurology 1985; 35: 931-934.

46. Can BR, Hume AL, Judson JA, Shaw NA. The assessment of severe head injury by short-latency somatosensory and brainstem auditory evoked potentials. Electroencephalogr Clin Neurophysiol 1986; 65: 188-195.

47. Nagao S, Kuyama H, Honma Y, et al. Prediction and evaluation of brainstem function my auditory brainstem responses in patients with uncal herniation. Surg Neurol 1987; 27: 81-86.

48. Starr A. Auditory brainstem responses in brain death. Brain 1976; 99: 543-554.

49. Trojaborg W, Jorgensen EO. Evoked cortical potentials in patients with isoelectric EEGs. Electroenceph Clin Neurophysiol 1973; 35: 301-309.

50. Starr A, Achor LJ. Auditory brain stem responses in neurological disease. Arch Neurol 1975; 32: 761-768.

51. Stockard JJ, Sharbrough FW. Unique contributions of short-latency somatosensory evoked potentials in patients with neurological lesions. Prog Clin Neurophysiol 1980; 7: 231-263.

52. Hecox K, Galambos R. BAEPs in human infants and adults. Arch Otolaryngol 1974; 99: 30-33.

53. Sohmer H, Feinmesser M. Routine use of electrocochleography (cochlear audiometry) on human subjects. Audiology 1973; 12: $167-173$

54. Mokotoff B, Schulman-Galambos C, Galambos R. BAEPs in children. Arch Otolaryngol 1977; 103: 38-43.

55. Smith LE, Simmons FB. Accuracy of BAEPs with hearing level unknown. Ann Otol Rhimol Laryngol 1982; 94: 266-267.

56. Starr A, Amlie RN, Martin WH, Sanders S. Development of auditory function in newborn infants revealed by BAEPs. Pediatrics 1977; 60: 831-839.

57. Hume AL, Cant BR, Shaw NA. Central somatrosensory conduction time in comatose patients. Ann Neurol 1979; 5: 379-384.

58. Drummond JC, Todd MM, Sangu M. The effect of high dose sodium thiopental on brain stem auditory and median nerve somatosensory evoked responses in humans. Anesthesiology 1985; 63: 249-254.
59. Hume AL, Cant BR. Central somatosensory conduction after head injury. Ann Neurol 1981; 10: 411-419.

60. Ropper AH, Miller DC. Acute traumatic midbrain hemorrhage. Ann Neurol 1985; 18: 80-86.

61. Zegers de Beyl D, Borenstein S, Bufaye P, Brunko E. Irreversible cortical damage in acute postanoxic coma: predictive value of somatosensory-evoked potentials. Transplantation Proceedings, Vol. XVI, 1984; 1: 98-101.

62. Chiappa KH, Hoch DB. Electrophysiologic Monitoring. In: Ropper $\mathrm{AH}$ ed. Neurological and Neurosurgical Intensive Care, Third edition, New York: Raven Press, Ltd., 1993, 147-183.

63. Walker AE, Diamond EL, Moseley J. The neuropathological findings in irreversible coma. J Neuropathol Exp Neurol 1975; 34: 295-323.

64. Eldridge PR, Pope T, Yeoman PM, et al. Somatosensory evoked potentials in intracranial hypertension: analysis of the effects of hypoxia. Neurosurg 1991; 75: 108-114.

65. Haupt WF, Erasmi-Korber H, Lanfermann H. Intraoperative recording of parietal SEP can miss hemodynamic infarction during carotid endarterectomy: a case study. Electroenceph Clin Neurophysiol 1994; 92: 86-88.

66. Macdonell RAL, Donnan GA, Bladin PF. A comparison of somatosensory and motor evoked potentials in stroke. Ann Neurol 1989; 25: 68-73.

67. Kandler RH, Jarratt JA, Venables GS. Clinical value of magnetic stimulation in stroke. Cerebrovase Dis 1991; 1: 239-244.

68. Zentner $\mathrm{J}$, Rhode $\mathrm{V}$. The prognostic value of somatosensory and motor evoked potentials in comatose patients. Neurosurg 1992; 31(3): 429-434.

69. Ying Z, Schmid UD, Schmid J, Hess CW. Motor and somatosensory evoked potentials in coma: analysis and relation to clinical status and outcome. J Neurol Neurosurg Psychiatry 1992; 55(6): 470-474.

70. Taniguchi M, Schramm J. Motor evoked potentials facilitated by an additional peripheral nerve stimulation. Electroenceph Clin Neurophysiol 1991; 43 (Suppl): 202-211.

71. Facco E, Munari M, Baratto F, Dona B, Giron GP. Somatosensory evoked potentials in severe head trauma. In: Rossini PM, Mauguiere F, eds. New Trends and Advanced Techniques in Clinical Neurophysiology, Amsterdam: Elsevier Publishers, 1990: 330-341. 